\title{
To save lives, initiative pushes for standardized diagnostic tools
}

Take your car into any repair shop and, chances are, the mechanics there have a computer that can interface with the vehicle's diagnostic system and pinpoint the problem.

"The question that the medical community should be asking is, 'why isn't there this level of compatibility among [diagnostic] devices used to save lives?"' says Steve Buchsbaum, deputy director of strategy at the Bill \& Melinda Gates Foundation's Global Health Discovery division. In December, the Gates Foundation kicked off an initiative to develop a common platform for point-of-care diagnostic devices for use in the developing world.

Less than $5 \%$ of deaths in developed nations are due to infectious disease. For the most part, patients have ready access to clinics linked to sophisticated laboratories with advanced diagnostic machinery.

In the world's poorest nations, however, more than $50 \%$ of deaths are from infectious diseases-a toll that might be reduced if the same diagnostic capability was brought to bear in the form of portable, easy-to-use devices. For example, according to projections by the Gates Foundation, a device capable of diagnosing syphilis might prevent 215,000 stillbirths. A malarial test, meanwhile, might save more than 2 million lives and prevent nearly 450 million unnecessary treatments due to misdiagnosis per year.

Standard diagnostic equipment for laboratories tends to be idiosyncratic in how it is used and what supplies it needs. Buchsbaum envisions point-of-care diagnostics for the developing world in the form of a single type of device that is 'open source', for which any company can develop specific assays and equipment. The Gates Foundation Grand Challenges in Global Health initiative is offering $\$ 30$ million in grants to develop such platforms and is accepting letters of inquiry through mid February.

The development of a common open-source platform for diagnostics would mean less training required among users and greater ease in obtaining supplies for these devices. New assays would therefore be cheaper to develop and would perhaps gain swifter regulatory approval, Buchsbaum says.

The most promising form for the devices is that of a shoe-box-sized 'reader' that analyzes samples such as blood, saliva or urine submitted on a microfluidic card. These types of tools come out of research jumpstarted by the US Defense Advanced Research Projects Agency (DARPA) in the 1990s for potential military application.
Paul Yager, a professor of bioengineering at the University of Washington who has a separate Gates Foundation grant, hopes to have a reader dubbed the DxBox ready for market in two years that can perform polymerase chain reaction as well as immunoassay analysis for six pathogens.

Still, "developing a common platform, even if we think we know what shape it's going to take, is not going to be an easy task," says Mickey Urdea, managing partner of Halteres Associates, LLC, a consulting firm that specializes in bioscience diagnostics.

The effort would require standardizing the size, type (blood, saliva or sputum) and content (salt levels or water levels) the devices would accept. This can be tricky, given that the various pathogens, test types and environments may require radically different samples.

However, perhaps the most daunting element is the bioscience industry that would produce the devices. Standard laboratory equipment tends to be idiosyncratic, because the companies that develop it are very protective

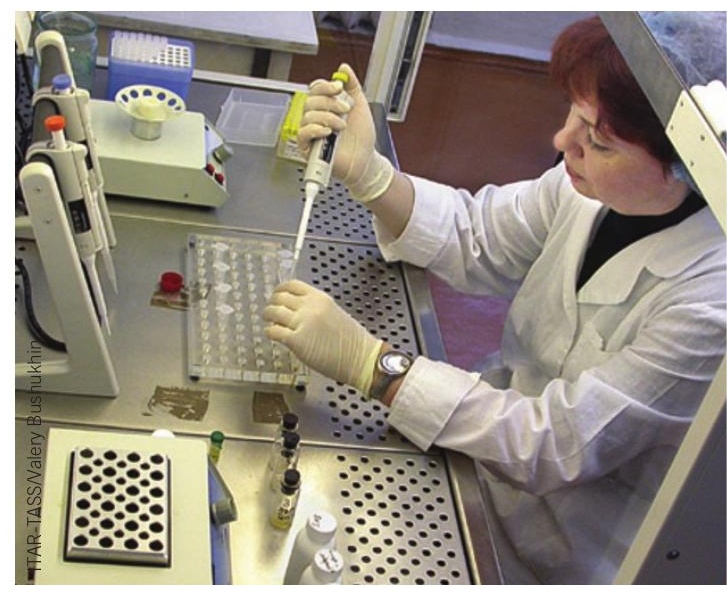

Chain reaction: Diagnostics are pricey

of their intellectual property claims on that equipment and the associated assays. Moving to an open-source system would mean sharing technology — a polar-opposite business model, Urdea says.

Stu Hutson, Gainesville, Florida

\section{Penalty payouts from pharma rise}

Last September, when Pfizer agreed to pay out a record $\$ 2.3$ billion for illegally marketing the drug Bextra, the news made headlines around the world. But although the figure represents the largest criminal fine of its kind, it is in reality only part of a larger trend of big penalties paid by pharmaceutical companies.

The government had accused the company of promoting Bextra, a painkiller that was ultimately withdrawn from the market, for off-label uses. A
1962 US law bans companies from promoting approved drugs beyond their specific uses.

In a recent roundup of some of the biggest payouts related to illegal marketing, Bloomberg news stressed that many of these companies had pledged they would stop promoting drugs for unauthorized purposes. The following list captures some of the highest sums from the past five years:

\begin{tabular}{|llll|}
\hline Company & Date of penalty & Drug(s) & Amount, in millions \\
\hline Pfizer & September 2009 & Bextra, others & $\$ 2,300$ \\
Eli Lilly & January 2009 & Zyprexa & $\$ 1,415$ \\
Serono & October 2005 & Serostim & $\$ 704$ \\
Purdue & May 2007 & Oxycontin & $\$ 634$ \\
Schering-Plough & August 2006 & $\begin{array}{l}\text { Temodar, } \\
\text { Intron A }\end{array}$ & $\$ 435$ \\
Pfizer (Warner-Lambert) & May 2004 & Neurontin & $\$ 430$ \\
Cephalon & September 2008 & Actiq, Gabitril, & $\$ 425$ \\
& & Provigil & \\
\hline
\end{tabular}

Source: Bloomberg/Federal court records 